\title{
Tramadol Induced Paradoxical Hyperalgesia
}

Seong Heon Lee, MD, Soo Young Cho, MD, Hyung Gon Lee, MD, PhD, Jeong II Choi, MD, $\mathrm{PhD}$, Myung Ha Yoon, MD, PhD, and Woong Mo Kim, MD, PhD

From: Department of Anesthesiology and Pain Medicine, Chonnam National University Medical School, South Korea

Dr. SH Lee and Dr. Cho are Clinica Professor, Department of Anesthesiology and Pain Medicine, Chonnam National University Hospital, Gwangju, South Korea.

Dr. HG Lee and Dr. Kim are Assistant Professor, Department of Anesthesiology and Pain Medicine, Chonnam National University Hospital and Medical School, Gwangju, South Korea. Dr. Choi is Associate Professor, Department of Anesthesiology and Pain Medicine, Chonnam Nationa University Hospital and Medical School,

Gwangju, South Korea. Dr. Yoon is

Professor, Department of Anesthesiology and Pain Medicine, Chonnam National University Hospital and Medical School, Gwangju, South Korea.

Address Correspondence: Woong Mo Kim, MD, PhD

Dept. of Anesthesiology and Pain Medicine Chonnam National University Medical School

42 Jebong-ro, Dong-gu, Gwangju 501-757, South Korea

Email: kimwm@jnu.ac.kr

Disclaimer: There was no external funding in the preparation of this manuscript. Conflict of interest: None.

Manuscript received: 09-06-2012 Accepted for publication: 10-11-2012

Free full manuscript: www.painphysicianjournal.com
Opioids have been the mainstay analgesics for postoperative, cancerous, and chronic noncancerous pain. Common concerns regarding the use of opioids include the development of physical dependence and addiction. However, as a potential complication of opioid therapy, opioid-induced hyperalgesia $(\mathrm{OIH})$ is often overlooked. That is, patients receiving opioids to control their pain may paradoxically become more sensitive to pain as a consequence of opioid therapy. $\mathrm{OlH}$ is a very important issue because it may complicate the clinical course of pain treatment and even worsen the suffering of patients receiving opioids because of the development of excruciating pain.

Three $\mathrm{OlH}$ types were defined: 1) in the context of maintenance dosing and withdrawal, 2) at very high or escalating doses, and 3) at ultra-low doses. In the literature, most attention has been paid to the first 2 forms, and almost all cases of reported $\mathrm{OlH}$ have been ascribed to morphine administration. The third form of $\mathrm{OlH}$ has not been documented in humans, although it has been observed in animals.

We present 2 cases of $\mathrm{OlH}$ resulting from administration of tramadol, which is a synthetic analogue of codeine and exhibits 10-fold less affinity for mu-opioid receptors, in patients suffering from chronic pain. The 2 cases presented herein imply the importance of recognizing $\mathrm{OlH}$ in patients medicated with tramadol if analgesic effects are lost in the context of dose titration, when generalized pain is reported without any evidence of disease exacerbation.

While $\mathrm{OlH}$ associated with ultra-low dose opiates seems to be quite rare, if it is suspected, switching to other drugs and an appropriate treatment should be considered

Key words: Opioid-induced hyperalgesia, opioids, chronic pain, serotonin syndrome, tramadol, ketamine.

Pain Physician 2013; 16:41-44 or decades, opioids have been the mainstay analgesics for postoperative, cancerous, and chronic non-cancerous pain. Common concerns regarding the use of opioids include the development of physical dependence and addiction, although the former does not foreshadow harm and the latter is a possible but unlikely event (1). Another problem, however, has recently drawn attention as a complication of opioid therapy, and is often referred to as opioid-induced hyperalgesia (OIH) (2). That is, patients receiving opioids to control their pain may paradoxically become more sensitive to pain as a consequence of opioid therapy. Thus, opioid therapy may be a double-edged sword showing an initial strong analgesic effect but gradually increasing pain as a result of compensatory upregulated pronociceptive pathways (3). Although physician monitoring of addiction, abuse, and diversion are frequently emphasized, $\mathrm{OIH}$ is often overlooked 
as a potential complication of opioid therapy. OIH is a very important issue because it may complicate the clinical course of pain treatment and even worsen the suffering of patients receiving opioids because of the development of excruciating pain.

In a qualitative systematic review (2), 3 OlH types were defined: 1 ) in the context of maintenance dosing and withdrawal, 2) at very high or escalating doses, and 3) at ultra-low doses. In the literature, most attention has been paid to the first 2 forms, and almost all cases of reported OIH have been ascribed to morphine administration. However, to the best of the authors' knowledge, the third form of OlH has not been documented in humans, although it has been observed in animals. We herein report 2 cases of $\mathrm{OlH}$ resulting from administration of tramadol, which is a synthetic analogue of codeine and exhibits 10-fold less affinity for mu-opioid receptors (4), in patients suffering from chronic pain.

\section{Case 1}

A 67-year-old male patient with a one-year history of well-controlled postherpetic neuralgia in his right arm and shoulder of the C5 sensory dermatome complained of recent aggravation of his pain, which was rated as $7 / 10$ on a numeric rating scale (NRS; $0=$ no pain, $10=$ worst pain imaginable) since one week previously. Mental status and motor and sensory functions were intact, and no signs of muscular hyperactivity, such as tremor or myoclonus, were noted. His previous medications included tramadol (400 mg/day) and pregabalin ( $225 \mathrm{mg} / \mathrm{day}$ ). A stepwise increase of pregabalin to $600 \mathrm{mg} /$ day and the addition of oxycodone up to $40 \mathrm{mg} /$ day for 2 weeks or transdermal fentanyl up to $25 \mu \mathrm{g} / \mathrm{h}$ for the following 2 weeks did not improve his pain. A detailed history revealed that the pain was generalized, albeit most prominent in the right arm; accompanied by diaphoresis, chill, and rhinorrhea; and peaked at 2 hours after medication administration. The pain was burning in nature and sensitive to light touch or clothing. We diagnosed his condition as $\mathrm{OIH}$ and began intravenous administration of midazolam ( $2 \mathrm{mg}$ ) followed by ketamine, which was started at a dose of $0.5 \mathrm{mg} / \mathrm{kg}$ for one hour every day. The dose of ketamine was increased when symptom relief was insufficient (based on NRS and its duration) and side effects were acceptable. Over a 12-day course, the ketamine was increased to $0.75 \mathrm{mg} / \mathrm{kg}$ and his generalized pain and autonomic symptoms were completely resolved. The patient described that the burning pain was decreased to 1 to 2 on the NRS. The patient was being maintained on oral medication including pregabalin, a tricyclic antidepressant, and tianeptine at the 2-year follow-up visit.

\section{Case 2}

A 57-year-old female patient complained of generalized pain with diaphoresis and irritability since 3 to 4 weeks previously. She had been prescribed tramadol (300 mg/day) and acetaminophen (1950 mg/day) for 4 years to relieve her left buttock pain attributable to the sacroiliac joint. Otherwise, her past medical history was negative. She described her pain as aching and hyperalgesic in nature, and it was aggravated after medication administration, rating 6 on the NRS. Her mental status was clear and physical examination revealed no neurologic abnormality or neuromuscular hyperactivity. An increase of tramadol and addition of pregabalin and a tricyclic antidepressant resulted in no improvement. We diagnosed her condition as $\mathrm{OlH}$ and began intravenous administration of midazolam $(2 \mathrm{mg}$ ) followed by ketamine $(0.5 \mathrm{mg} / \mathrm{kg})$ for one hour every day. The dose of ketamine was gradually increased up to $0.8 \mathrm{mg} / \mathrm{kg}$ during a 14-day treatment. Two weeks later, her generalized pain and diaphoresis were abolished, and she was discharged with prescriptions of pregabalin, a tricyclic antidepressant, and acetaminophen. At the oneyear follow-up visit, she complained of pain limited to the left buttock that had waxed and waned for several years.

\section{Discussion}

Even though opioids have been used to treat pain for thousands of years, there are some problems with chronic administration including lack of evidence supporting their long-term effectiveness, adverse events, misuse, abuse, and OIH. In a recent systematic review, there was a paucity of data on the evidence for opioid therapy for chronic non-cancer pain $(5,6)$. However, only tramadol showed fair evidence for managing osteoarthritis $(5,6)$. Tramadol has been known to be suitable as a long-term treatment for moderate to severe pain because it has a low potential for abuse or dependence compared to other opioids (7). Nevertheless, chronic tramadol administration may also produce complicating events such as $\mathrm{OIH}$, as the 2 cases presented herein indicated. It is important to recognize OIH in patients medicated with tramadol if analgesic effects are lost in the context of dose titration, when generalized pain is reported without any evidence of disease exacerbation. While OIH associated with ultra-low dose opiates such 
as tramadol seems to be quite rare, if it is suspected, switching to other drugs and an appropriate treatment should be considered.

Tramadol is a synthetic, centrally acting analgesic agent that is structurally related to codeine and morphine (8), and possesses both opiate and monoaminergic effects. At the central level, tramadol acts as a weak opioid agonist although its affinity for mu-opioid receptors is 10-fold weaker than codeine's affinity for mu-opioid receptors (9). However, the active metabolite of tramadol, o-desmethyltramadol, has a far greater affinity than that of the parent compound (4). At the peripheral level, tramadol inhibits serotonin release and reuptake of norepinephrine and serotonin (8). The antinociceptive effects of tramadol are thought to result from the sum of these properties (10). In terms of toxicity, most side effects observed with tramadol treatment appear to be related to monoamine uptake inhibition rather than its opioid effects (11). Nevertheless, the affinity of tramadol for opioid receptors and its definitive role in tramadol-induced analgesia have been clearly demonstrated $(9,12)$; thus, the possibility of opioid side effects including $\mathrm{OIH}$, especially with long-term use, cannot be excluded. According to the literature $(1,2,13)$, several features observed in the reported cases may be clues to the diagnosis of $\mathrm{OlH}$. First, both patients complained of an increased intensity of pain above the preexistent pain level in spite of continued medication, and an increase in the opioid dose did not result in reduction of pain. Second, the pain described by the patients was not localized to the preexisting location, but was generalized and diffuse in nature. Consequently, we assume that this condition may be attributed to OIH produced by prolonged exposure to tramadol.

The differential diagnosis of this condition should be serotonin syndrome, which may be caused by excessive agonism of serotonin receptors following administration of tramadol (14). However, serotonin syndrome appears to be more common following either excessive use of or a combination of tramadol with selective serotonin reuptake inhibitors or tricyclic antidepressants (4). In addition, according to the Hunter Toxicity Criteria Decision Rules which is the most accurate criteria for the diagnosis of serotonin syndrome, clonus (spontaneous, inducible, and ocular) or tremor is the essential component (15). However, as described in the case, these signs were not exhibited in the patients, thus the serotonin syndrome could be ruled out.
Although the precise mechanisms that underlie the development of OIH remain to be elucidated, numerous animal studies identified various biochemical targets that undergo modifications in response to persistent opioid administration $(3,16)$. The neuroadaptations to chronic opioid exposure include the up-regulation of cholecystokinin in the rostral ventromedial medulla causing the activation of descending pain facilitation (17), increased expression of dynorphin, paradoxical activation of adenylate cyclase (AC) and protein kinase $\mathrm{C}$, and subsequent activation of the $\mathrm{N}$-methyl-Daspartic acid (NMDA) receptor system, and these changes appear to play an important role in $\mathrm{OIH}(3,16)$. The increased level of dynorphin resulting from ongoing stimulation of mu-opioid receptors reportedly enhances the release of excitatory neurotransmitters, such as glutamate, aspartate, substance $P$, and calcitonin generelated peptide from primary afferents $(18,19)$. The NMDA antagonist MK-801 blocked these responses and prevented the development of tolerance and OIH (20). Therefore ketamine, an NMDA antagonist, has been used to treat $\mathrm{OIH}$ and serves as an adjuvant to opioid therapy for managing chronic pain $(1,21,22)$. In the patients presented herein, we also administered ketamine intravenously, and this might have resulted in the alleviation of $\mathrm{OIH}$. In addition, the paradoxical activation of AC also increases CAMP in the locus ceruleus that regulates the activity of the autonomic nervous system, and appears to increase the intrinsic firing rate of their noradrenergic neurons (23). These changes probably contribute to the withdrawal symptoms mediated by an increased activity of the noradrenergic system (24). Accordingly, clonidine, an $\alpha-2$ adrenergic receptor agonist that down-regulate noradrenergic neuron activity, is very effective for the treatment of not only opioid withdrawal (25) but also OIH (26). Taken together, OIH and withdrawal syndrome share some similarities in neurochemical mechanism, thus we assumed that the autonomic symptoms of the patients presented here might result from the neurochemical adaptations to chronic tramadol administration.

\section{Conclusion}

OIH may develop as a consequence of long-term administration of tramadol, and intravenous ketamine may be helpful in these conditions. 


\section{References}

1. Silverman SM. Opioid induced hyperalgesia: Clinical implications for the pain practitioner. Pain Physician 2009; 12:679684.

2. Angst MS, Clark JD. Opioid-induced hyperalgesia: A qualitative systematic review. Anesthesiology 2006; 104:570-587.

3. Porreca F. Opiates - Pharmacology of Pain. In: Schmidt RF, Willis WD (ed) Encyclopedia of Pain. 1st ed. Springer, New York, 2007, pp 2504-2505.

4. Sansone RA, Sansone LA. Tramadol: Seizures, serotonin syndrome, and coadministered antidepressants. Psychiatry (Edgmont) 2009; 6:17-21.

5. Manchikanti L, Ailinani $\mathrm{H}$, Koyyalagunta Datta S, Singh V, Eriator I, Sehgal $\mathrm{N}$, Shah R, Benyamin R, Vallejo R, Fellows B, Christo PJ. A systematic review of randomized trials of long-term opioid management for chronic non-cancer pain. Pain Physician 2011; 14:91-121.

6. Manchikanti L, Vallejo R, Manchikanti KN, Benyamin RM, Datta S, Christo PJ. Effectiveness of long-term opioid therapy for chronic non-cancer pain. Pain Physician 2011; 14:E133-E156.

7. Knisely JS, Campbell ED, Dawson KS, Schnoll SH. Tramadol post-marketing surveillance in health care professionals. Drug Alcohol Depend 2002; 68:15-22.

8. Govind J. Tramadol hydrochloride. In Schmidt RF, Willis WD (eds). Encyclopedia of Pain. 1st ed. Springer, New York, 2007, pp 2504-2505.

9. Hennies $\mathrm{HH}$, Friderichs E, Schneider J. Receptor binding, analgesic and antitussive potency of tramadol and other selected opioids. Arzneimittel-Forschung 1988; 38:877-880.

10. Raffa RB, Friderichs E, Reimann W, Shank RP, Codd EE, Vaught JL. Opioid and nonopioid components independently contribute to the mechanism of action of tramadol, an 'atypical' opioid analgesic. J Pharmacol Exp Ther 1992; 26o:275-85.

11. Spiller HA, Gorman SE, Villalobos D, Benson BE, Ruskosky DR, Stancavage $M M$, Anderson DL. Prospective multicenter evaluation of tramadol exposure. J Toxicol Clin Toxicol 1997; 35:361-364.

12. Ide S, Minami M, Ishihara K, Uhl GR, Sora I, Ikeda K. Mu opioid receptor-dependent and independent components in effects of tramadol. Neuropharmacology 2006; 51:651-658.

13. Mao J, Price DD, Mayer DJ. Mechanisms of hyperalgesia and morphine tolerance: A current view of their possible interactions. Pain 1995; 62:259-274.

14. Dvir Y, Smallwood P. Serotonin syndrome: A complex but easily avoidable condition. Gen Hosp Psychiatry 2008; 30:284-287.

15. Dunkley EJ, Isbister GK, Sibbritt D, Dawson $\mathrm{AH}$, Whyte IM. The Hunter Serotonin Toxicity Criteria: Simple and accurate diagnostic decision rules for serotonin toxicity. Qjm 2003; 96:635-642.

16. Brush DE. Complications of long-term opioid therapy for management of chronic pain: The paradox of opioid-induced hyperalgesia. J Med Toxicol 2012; 8:387-392.

17. Xie JY, Herman DS, Stiller CO, Gardell LR, Ossipov MH, Lai J, Porreca F, Vanderah TW. Cholecystokinin in the rostral ventromedial medulla mediates opioidinduced hyperalgesia and antinociceptive tolerance. J Neurosci 2005; 25:409416.

18. Arcaya JL, Cano G, Gomez G, Maixner W, Suarez-Roca $H$. Dynorphin A increases substance $P$ release from trigeminal primary afferent C-fibers. Eur J Pharmacol 1999; 366:27-34

19. Gardell LR, Wang R, Burgess SE, Ossi- pov $\mathrm{MH}$, Vanderah TW, Malan TP Jr, Lai J, Porreca F. Sustained morphine exposure induces a spinal dynorphin-dependent enhancement of excitatory transmitter release from primary afferent fibers. J Neurosci 2002; 22:6747-6755.

20. Mao J, Price DD, Mayer DJ. Thermal hyperalgesia in association with the development of morphine tolerance in rats: Roles of excitatory amino acid receptors and protein kinase C. J Neurosci 1994; 14:2301-2312.

21. Mercadante S, Villari P, Ferrera P. Burst ketamine to reverse opioid tolerance in cancer pain. J Pain Symtom Manage 2003; 25:302-305.

22. Hong $\mathrm{BH}$, Lee $\mathrm{WY}$, Kim $\mathrm{YH}$, Yoon $\mathrm{SH}$, Lee WH. Effects of intraoperative low dose ketamine on remifentanil-induced hyperalgesia in gynecologic surgery with sevoflurane anesthesia. Korean J Anesthesiol 2011; 61:238-243.

23. Nestler EJ, Aghajanian GK. Molecular and cellular basis of addiction. Science 1997; 278:58-63.

24. Punch LJ, Self DW, Nestler EJ, Taylor JR. Opposite modulation of opiate withdrawal behaviors on microinfusion of a protein kinase $A$ inhibitor versus activator into the locus coeruleus or periaqueductal gray. J Neurosci 1997; 17:85208527.

25. Maldonado R. Participation of noradrenergic pathways in the expression of opiate withdrawal: Biochemical and pharmacological evidence. Neurosci Biobehav Rev 1997; 21:91-104.

26. Koppert W, Sittl R, Scheuber K, Alsheimer M, Schmelz M, Schuttler J. Differential modulation of remifentanilinduced analgesia and postinfusion hyperalgesia by S-ketamine and clonidine in humans. Anesthesiology 2003; 99:152159. 